\title{
ASSESSMENT OF VULNERABILITY TO SEAWATER INTRUSION FOR THE COASTAL AQUIFER OF DAR ES SALAAM (TANZANIA)
}

\section{Giuseppe Sappa ${ }^{1}$}

\section{Flavia Ferranti ${ }^{1}$}

\section{Francesco Maria De Filippi ${ }^{1}$}

${ }^{1}$ DICEA, Department of Civil and Environmental Engineering, Sapienza University of Rome, Rome, Italy

\begin{abstract}
Groundwater represents worldwide the main reserve of freshwater for human needs. The increasing demand, combined with the use of unsustainable systems for groundwater management, leads to a remarkable decay in its quality and quantity, especially in many cities of the Global South, where the fast urban growing frequently bring to environmental critical issues as the case of seawater intrusion for coastal aquifers. Dar es Salaam, in Sub-Saharan Africa, is one of these cities, with more than 4 million of inhabitants and a population growth rate of about 8 per cent per year. Due to the urban pressure on the aquifer, the city is now facing a considerable saline intrusion along the coastline, with depletion of groundwater resources and contamination of pumping wells. Aim of this paper is to apply and test the GALDIT method for the assessment of coastal aquifer vulnerability to seawater intrusion, starting from data and measures collected from 2011 to 2013 during the "Adapting to Climate Change in Coastal Dar es Salaam (ACC-DAR) project. The GALDIT is a weights and rating based method that consider six parameters to compute a vulnerability to seawater intrusion index according to a specific numerical ranking. The key parameters are the following ones: Groundwater occurrence, Aquifer hydraulic conductivity, Level of the groundwater above the mean sea level, Distance from the shore, Impact of existing status of seawater intrusion in the area and Thickness of the aquifer. Providing different weights and ratings the GALDIT method allows to evaluate the relative impact of each factor, starting from different hydrogeological settings. The results for Dar es Salaam study case show the presence of all the classes (Low, Moderate and High). High and moderate vulnerability classes are rather more concentrated in the northern part of the city. In this context, the assessment of coastal aquifer vulnerability to seawater intrusion in the area of Dar es Salaam might turn out to be a helpful basic information in support of groundwater local policies, for a proper and more sustainable use of the resource.
\end{abstract}

Keywords: vulnerability assessment, seawater intrusion, GALDIT method, coastal aquifer, Africa

\section{INTRODUCTION}

Groundwater is the largest reserve of freshwater available in the Earth, and thus plays a crucial role in the water supply of the population worldwide, providing more than $50 \%$ of water supply of the world population [1]. 
Groundwater is the major source to meet domestic, industrial and agricultural purposes in many cities of the Global South, not only in arid or semi-arid climates but also in tropical ones, due to the progressive quantitative and qualitative deterioration of surface water [2-3]. However, population growth, increasing urbanization, industrialization and tourism, and climatic changes have caused an intensive exploitation of groundwater resources leading the aquifers become more vulnerable to seawater intrusion [4].

The city of Dar es Salaam (Tanzania) is one of the fastest-growing cities in sub-Saharan Africa. The city faces periodic water shortages, during which water demand is hardly satisfied. Only one third of the households receives water directly from the public water supply and water needs relies increasingly on groundwater. The sectors that represent the key/central aspects of vulnerability for Dar es Salaam, are water supply, waste management, drainage, and health services [5-6]. In such contexts, the increasing pressure on aquifers linked to growing urbanization, the inefficiency of adequate infrastructures, as well as the effects of climatic changes on rainfall, frequently determine a series of social and environmental criticalities such as water table depletion, groundwater quality contamination, land subsidence, seawater intrusion along the coastline [7-8]. This paper presents a vulnerability assessment to seawater intrusion of the Dar es Salaam's coastal aquifer using the GALDIT index model, in order to better manage these groundwater resources in coastal plains affected by seawater intrusion.

This work deals with the results carried out in the framework of the Adapting to Climate Change in Coastal Dar es Salaam (ACC-DAR) project, a three-year project co-funded by the European Commission that aims to improve the effectiveness of municipal initiatives for supporting coastal peri-urban populations in their efforts to adapt to the impacts of Climate Change.

\section{GEOLOGICAL AND HYDROGEOLOGICAL SETTING}

The region of Dar es Salaam is divided into the three districts of Kinonondoni, Ilala and Temeke. The study area covers a surface of approximately $260 \mathrm{~km}^{2}$. It extends along a $40 \mathrm{~km}$ stretch of coastline to the north of the city center, and includes a part of the city center, and some peri-urban areas. The eastern boundary is the Indian Ocean, the western boundary is the Dar es Salaam Plateau, which rises west of the Ocean along the entire study area up to the Pugu Hills, the southern and northern hydrogeological boundaries are, respectively, the Mzinga River and the Nyakasangwe River [4]. The geological setting of the study area includes unconsolidated sediments of Neogene and Quaternary ages. In the coastal region of Dar es Salaam, the quaternary deposits can be divided into three geological layers: alluvial, coastal plain, and coral reef limestone deposits (Fig. 1). Alluvial deposits fill the valleys of the Mzinga, Kizinga, and Msimbazi rivers. They consist of an alternation of fine and coarse-grained sands, clay, and sometimes gravel and pebbles. The coastal plain consists of unconsolidated sediments, predominantly sandy, with evidence of several marine intercalations. The presence of coralline limestone is found along the coastal strip. Carbonate rocks are present as fringing reefs and raised reefs. The groundwater reservoir is located within the coastal plain in the quaternary sediments. The aquifer system is made of two main aquifers, both from Quaternary: an upper unconfined sand aquifer and a lower semiconfined sand aquifer, separated by a clay aquitard. The sediment type for both aquifers is almost the same, and consists of quaternary deposits from Pleistocene to the recent age. The unconfined aquifer is considered the most important aquifer for water supply. 
It consists of fine to medium sand, with varying percentages of silt and clay. For the high percentage of sand, it is defined a sandy aquifer. The lower, semi-confined aquifer consists of medium to coarse sands. The lower aquifer overlies the substratum formed by Mio-Pliocene clay-bound sand and gravel and kaolinitic Pugu sandstones [9].

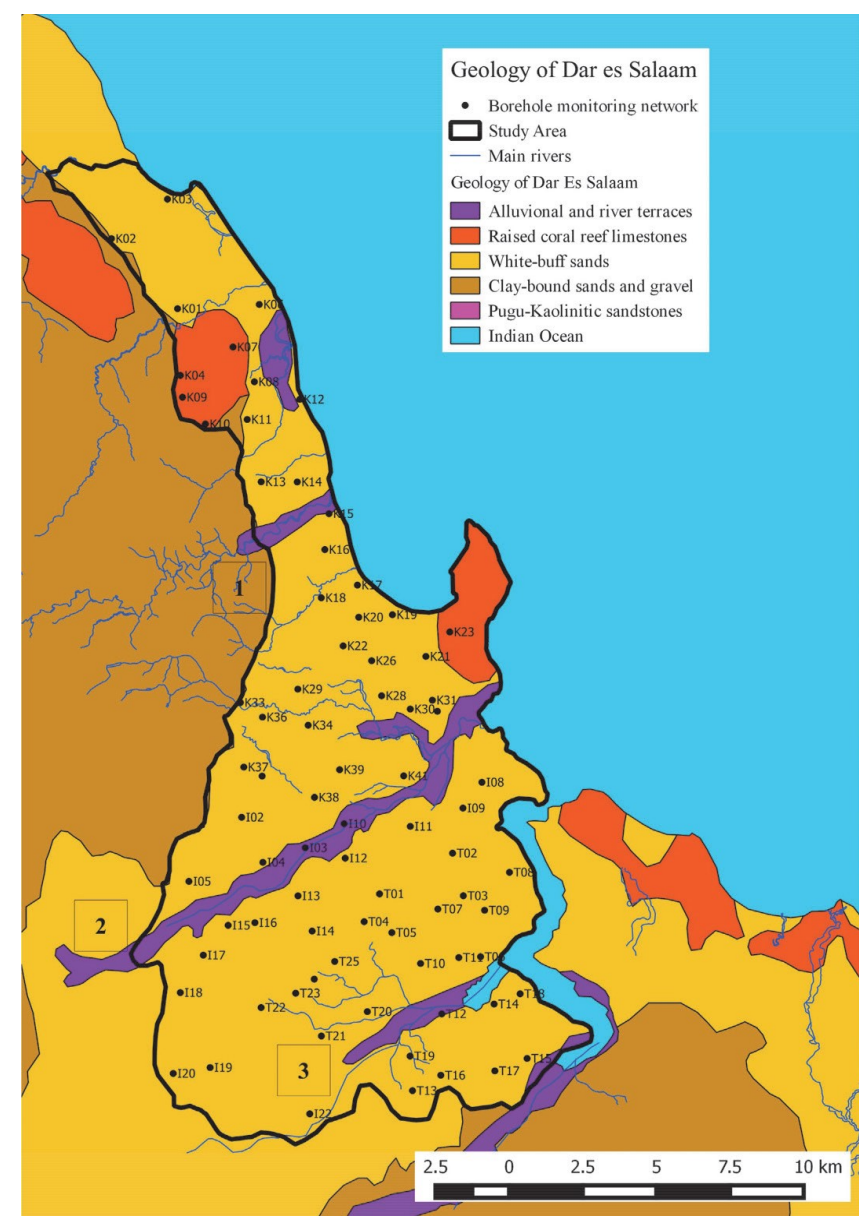

Figure 1. Simplified hydro-geological map of the study area

\section{THE GALDIT METHOD}

The GALDIT vulnerability index [10-11] is an indicator-based model to assess vulnerability of coastal aquifers to seawater intrusion. In this model, six factors, which control seawater intrusion for different hydrogeological settings, are used to compute the final GALDIT index. The method is based on a numerical ranking system with different weights and ratings in order to define the relative impact of each factor on seawater intrusion process (Tab. 1). The key parameters of the GALDIT index are [1011]: Groundwater occurrence (aquifer type: unconfined, confined and leaky confined), Aquifer hydraulic conductivity, Level of the groundwater above the mean sea level, Distance from the shore (distance inland perpendicular from shoreline), Impact of existing status of sea water intrusion in the area, Thickness of the aquifer.

The degree of seawater intrusion is mainly due to the nature of the groundwater occurrence [12]. Consequently, the disposition and typology of the aquifer are fundamental to assign the rating for the parameter $G$. The rate of water flow in the aquifer is measured by the aquifer hydraulic conductivity. Higher the rating of 
parameter A, higher the aquifer hydraulic conductivity, greater will be the extent of seawater intrusion. The rating for the parameter $\mathrm{L}$ is assigned with respect to the variations observed in the groundwater level, averaged over a long period, in the study area. The rating value for the parameter D generally decreases with the increasing perpendicular distance from the shoreline.

Table 1: Indicators, weights and ratings of the GALDIT method (adapted from [11])

\begin{tabular}{|c|c|c|c|c|}
\hline \multirow{2}{*}{ Indicator } & \multirow{2}{*}{ Weight } & \multicolumn{2}{|c|}{ Indicator Variables } & \multirow[t]{2}{*}{ Importance Rating } \\
\hline & & Class & Range & \\
\hline \multirow{4}{*}{$\begin{array}{c}\text { Groundwater occurrence / } \\
\text { Aquifer type }\end{array}$} & \multirow{4}{*}{1} & Confined aquifer & - & 10 \\
\hline & & Unconfined aquifer & - & 7.5 \\
\hline & & Leaky confined Aquifer & - & 5 \\
\hline & & Bounded Aquifer & - & 2.5 \\
\hline \multirow{4}{*}{$\begin{array}{l}\text { Aquifer Hydraulic Conductivity } \\
\qquad(\mathrm{m} / \text { day })\end{array}$} & \multirow{4}{*}{3} & High & $>40$ & 10 \\
\hline & & Medium & $10-40$ & 7.5 \\
\hline & & Low & $5-10$ & 5 \\
\hline & & Very Low & $<5$ & 2.5 \\
\hline \multirow{4}{*}{$\begin{array}{l}\text { Height of groundwater Level } \\
\text { above asl (m) }\end{array}$} & \multirow{4}{*}{4} & High & $<1.0$ & 10 \\
\hline & & Medium & $1.0-1.5$ & 7.5 \\
\hline & & Low & $1.5-2.0$ & 5 \\
\hline & & Very Low & $>2.0$ & 2.5 \\
\hline \multirow{4}{*}{$\begin{array}{l}\text { Distance from shore / High Tide } \\
\text { (m) }\end{array}$} & \multirow{4}{*}{4} & Very small & $<500$ & 10 \\
\hline & & Small & $500-750$ & 7.5 \\
\hline & & Medium & $750-1000$ & 5 \\
\hline & & Far & $>1000$ & 2.5 \\
\hline \multirow{4}{*}{$\begin{array}{c}\text { Impact status of existing } \\
\text { seawater intrusion } \\
\frac{\mathrm{Cl}^{-}}{\left(\mathrm{HCO}_{3}^{-}+\mathrm{CO}_{3}^{2-}\right)}\end{array}$} & \multirow{4}{*}{1} & High & $>2.0$ & 10 \\
\hline & & Medium & $1.5-2.0$ & 7.5 \\
\hline & & Low & $1-1.5$ & 5 \\
\hline & & Very Low & $<1.0$ & 2.5 \\
\hline \multirow{4}{*}{$\begin{array}{l}\text { Aquifer Thickness (saturated) } \\
(\mathrm{m})\end{array}$} & \multirow{4}{*}{2} & Large & $>10$ & 10 \\
\hline & & Medium & $7.5-10$ & 7.5 \\
\hline & & Small & $5-7.5$ & 5 \\
\hline & & Very small & $<5$ & 2.5 \\
\hline
\end{tabular}

The ratio of $\left[\mathrm{Cl}^{-}\right] /\left[\mathrm{HCO}_{3}{ }^{-}+\mathrm{CO}_{3}{ }^{2-}\right]$, is often used to assess the magnitude of contamination by the intrusion of seawater in coastal aquifers. As a matter of fact, chloride is usually the dominant ion in the seawater, whereas its concentration is much less in fresh groundwater. At the same time, bicarbonate is found in large quantities in fresh groundwater. The ratio of these two ions is used to assign a rating value for the parameter I. The last parameter $\mathrm{T}$ is related to the aquifer thickness: larger the aquifer thickness, larger will be the volume of seawater intrusion. The importance of each 
parameter is defined through its weight (from a minimum of 1 to a maximum of 4 ) and a ranking scale of values (ranging from 2.5 to 10), depending on site-specific conditions, is suggested for each parameter. It is important to highlight that the process leading to the choice of the main indicators and ratings was totally "democratic". In fact, all the parameters and their weights, used for GALDIT method, were chosen through extensive discussions and consultations with lots of experts, academicians etc.

\section{APPLICATION OF THE GALDIT METHOD TO THE STUDY AREA}

In the urban area of Dar es Salaam, data coming from 51 wells have been analysed in order to evaluate the seawater intrusion vulnerability using GALDIT method. All the wells, belonging to the Dar es Salaam regional area, are located in three different districts: Kinondoni, Ilala and Temeke. As regards to the G parameter, a value of 7.5 was assigned to all the points. This choice was due to the presence of a multiple aquifer system in the study area. In this peculiar case, Chachadi and Lobo Ferreira (2005) suggest to adopt the highest rating for the Groundwater occurrence/Aquifer type, which is 7.5 for Unconfined Aquifer.

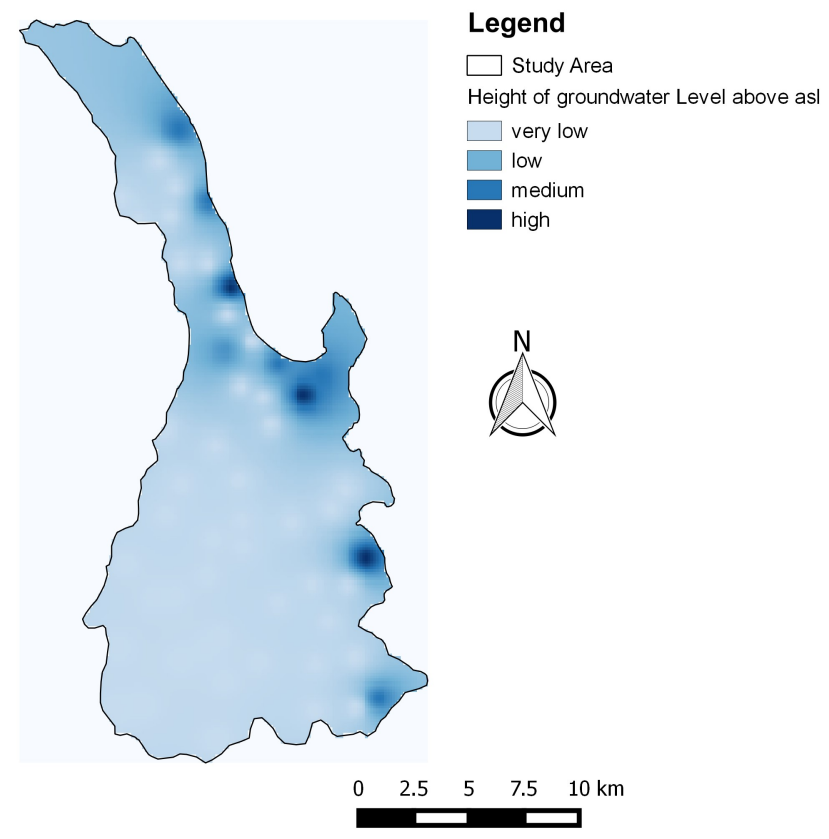

Figure 2. Spatial distribution of water level ( $\mathrm{m}$ asl) in the study area aquifer for the year 2012

The aquifer hydraulic conductivity (A) is related to the flowing rate of water in the aquifer. Starting from geological data in the area and hydrogeological data previously acquired [3], different average values of hydraulic conductivity have been assigned to the two main aquifers. In particular, the values are, respectively, $2,5 \mathrm{~m} / \mathrm{d}$ for the lower semi-confined aquifer and 3,0 $\mathrm{m} / \mathrm{d}$ for the upper unconfined one, resulting in a single value assignment of 2,5 for the hydraulic conductivity rating to the entire area. 


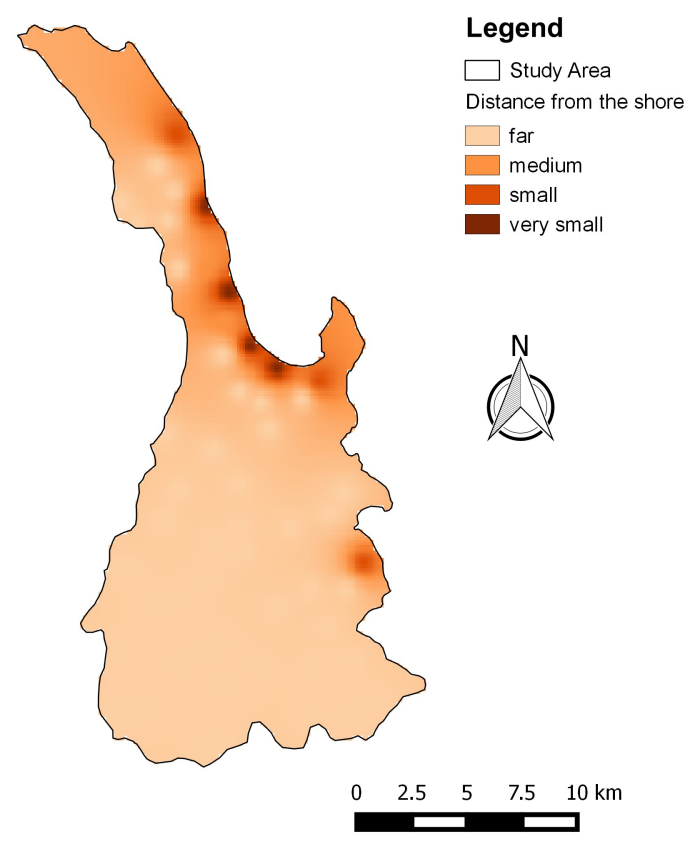

Figure 3. Spatial distribution of the distance from shore in the study area aquifer

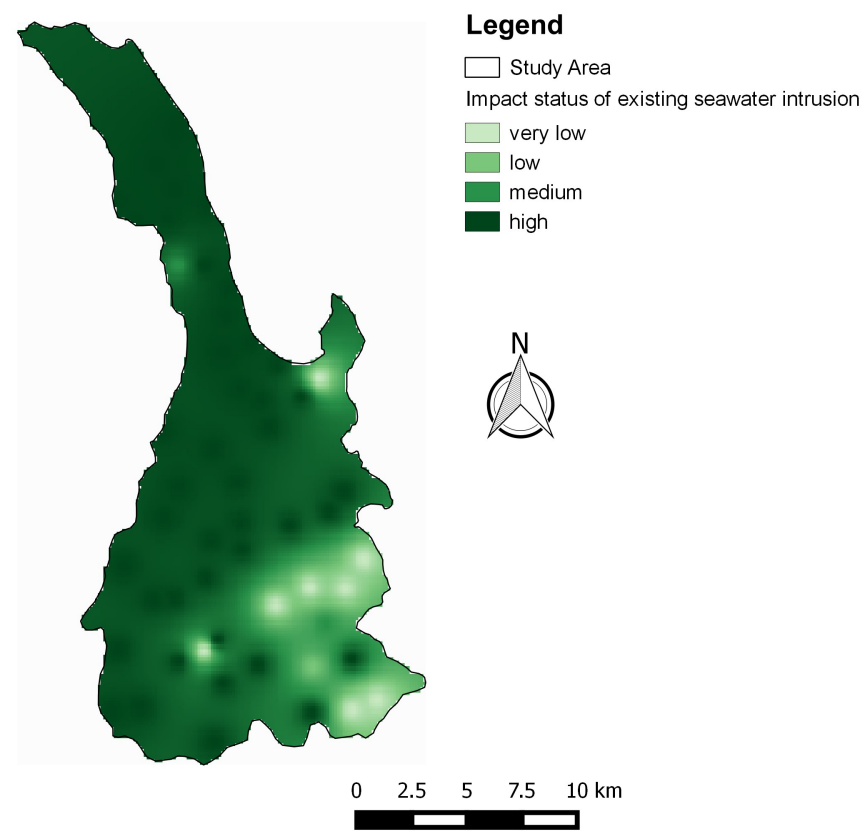

Figure 4. Spatial distribution of groundwater $\left[\mathrm{Cl}^{-}\right] /\left[\mathrm{HCO}_{3}{ }^{-}+\mathrm{CO}_{3}{ }^{2-}\right]$ ratio in the study area aquifer for the year 2012

The level of groundwater with respect to mean sea elevation (L) was assessed for each well as the difference between the ground level and the SWL measured in June 2012. The related ratings range from 2.5 (very low) to 10 (high) in the study area (Fig. 2). Data referred to the distance from the shoreline (D) were available for each well yielding to lower ratings for points far from the shore. As the area of Dar Es Salaam is 
very extensive, covering about $260 \mathrm{~km}^{2}$, the majority of wells have a distance greater than $1 \mathrm{Km}$ and, consequently, an importance rating of 2.5 (Fig. 3). The impact of existing status of seawater intrusion (I) has been evaluated through the well's chemical data using the ratio $\left[\mathrm{Cl}^{-}\right] /\left[\mathrm{HCO}_{3}{ }^{-}+\mathrm{CO}_{3}{ }^{2-}\right]$ proposed by Chachadi and Lobo Ferreira. The higher importance rating was assigned to the most part of wells highlighting a strong existing impact of seawater intrusion in the area of Dar es Salaam (Fig. 4). For the T indicator, as the unconfined aquifer in the study area presents a thickness ranging from 5 to $50 \mathrm{~m} \mathrm{[9]}$, a value of 10 was prudently assigned to the whole area.

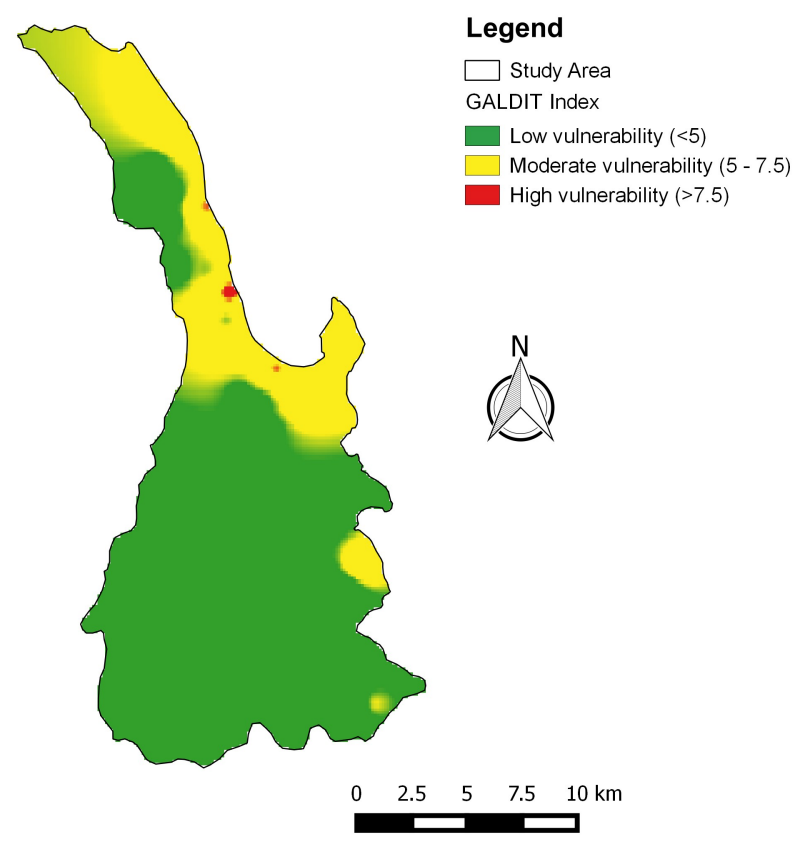

Figure 5. Map of the GALDIT index score of vulnerability classes for the year 2012

At last, the GALDIT vulnerability index was assessed for the coastal aquifer of Dar es Salaam area (Fig. 5). Mapping results show the presence of the low vulnerability class in the internal areas, far from the coast, mostly in the south of the study area. On the contrary, northern areas result to be more vulnerable to seawater intrusion, most of all nearby the Msasani Bay, where small zones are characterized by a high vulnerability index.

\section{CONCLUSION}

In this paper, the GALDIT method was used to assess the vulnerability to seawater intrusion for the coastal aquifer of Dar es Salaam, in Tanzania. The city recently had a significant urbanization and in the future may face an increasing groundwater depletion. The vulnerability assessment for the coastal aquifer of Dar es Salaam area seems to confirm this potential trend, highlighting how the most vulnerable areas are concentrated in the north of the city. Therefore, the application of GALDIT method result to be a useful tool in order to provide a general screening of seawater intrusion risk in monitoring policies, especially for urban areas. 


\section{REFERENCES}

[1] Margat J., Les eaux souterraines: une richesse mondiale, BRGM Éditions/UNESCO, Paris, 2006.

[2] Llamas M.R., Martinez-Santos P., Intensive Groundwater Use: Silent Revolution and Potential Source of Social Conflicts, Journal of Water Resources Planning and Management, vol. 131/issue 5, pp 337-341, 2005.

[3] Van Camp M.F., Mjemah I.C., Alfarrah N., Walraevens K., Modeling approaches and strategies for data-scarce aquifers: Example of the Dar es Salaam aquifer in Tanzania, Hydrogeology Journal, vol. 21/issue 2, pp 341-356, 2012.

[4] Sappa G., Ergul S., Ferranti F., Sweya L.N., Luciani G., Effects of seasonal change and seawater intrusion on water quality for drinking and irrigation purposes, in coastal aquifers of Dar es Salaam, Tanzania, Journal of African Earth Sciences, vol. 105, pp 64$84,2015$.

[5] Sappa G., Luciani G., Groundwater management in Dar Es Salam coastal aquifer (Tanzania) under a difficult sustainable development, WSEAS Transactions on Environment and Development, vol. 10, pp 465-477, 2014.

[6] Sappa G., Luciani G., Sustainability of groundwater management in the coastal plain of Dar es Salaam (Tanzania), Rendiconti Online Societa Geologica Italiana, vol. 35, pp 264-267, 2015.

[7] Sappa G., Ferranti F., Ergul S., Ioanni G., Evaluation of the groundwater active recharge trend in the coastal plain of Dar es Salaam (Tanzania), Journal of Chemical and Pharmaceutical Research, vol. 5/issue 12, pp 548-552, 2013.

[8] Sappa G., Trotta A., Vitale S., Climate Change Impacts on Groundwater Active Recharge in Coastal Plain of Dar es Salaam (Tanzania), Engineering Geology for Society and Territory, vol. 1: Climate Change and Engineering Geology, pp 177-180, 2015.

[9] Mjemah I.C., Hydrogeological and Hydrogeochemical Investigation of a Coastal Aquifer in Dar es Salaam, Tanzania, Ph.D. Thesis, Ghent University Press, Ghent, Belgium, 2007.

[10] Lobo-Ferreira J.P., Chachadi A.G., Catarina D., Diamantino C., Henriques M.J., Assessing aquifer vulnerability to seawater intrusion using GALDIT method: Part 1. In: IAHS and LNEC proceedings of the fourth interceltic colloquium on hydrology and management of water resources, Portugal, 2005.

[11] Lobo-Ferreira J.P., Chachadi A.G., Assessing aquifer vulnerability to seawater intrusion using GALDIT method: part 2. In: IAHS and LNEC proceedings of the fourth interceltic colloquium on hydrology and management of water resources, Portugal, 2005 .

[12] Sherif M.M., Hamza K.I., Mitigation of seawater intrusion by pumping brackish water, Transport Porous Media, vol. 43/issue 1, pp. 29-44, 2001. 